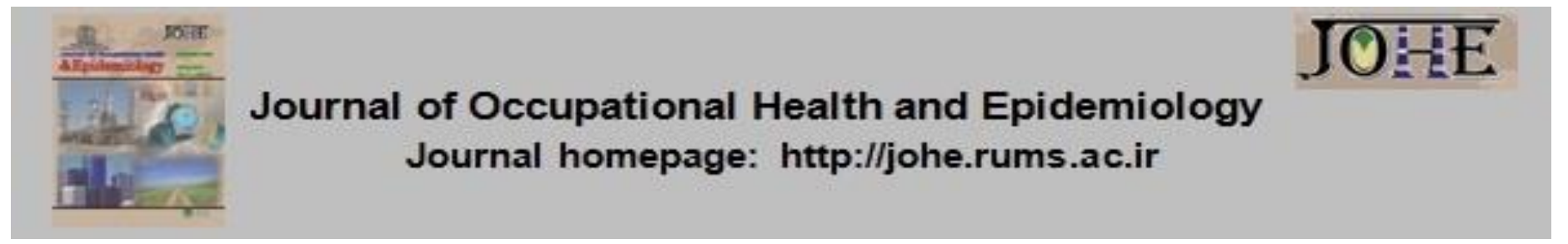

\title{
Occupational Physical Activity and Health-Related Quality of Life among Nigerian Vocational-Skilled Workers
}

\author{
Taofeek O. Awotidebe ${ }^{1 *}$, Adewale L. Oyeyemi ${ }^{2}$, Macellina Y. ljadunola ${ }^{3}$, Funminiyi S. Olatoye ${ }^{4}$, \\ Adeyemi S. Adejumobi ${ }^{5}$, Foluke T. Akinogbe ${ }^{6}$, Adekola J. Odunlade ${ }^{6}$, Rufus A. Adedoyin ${ }^{7}$ \\ 1. Assistant Prof., Dept. of Medical Rehabilitation, College of Health Sciences, Obafemi Awolowo University, lle - Ife, Nigeria. \\ 2. Professor, Dept. of Physiotherapy, College of Medical Sciences, University of Maiduguri, Maiduguri, Nigeria. \\ 3. Assistant Prof., Dept. of Community Health, College of Health Sciences, Obafemi Awolowo University, Ile - Ife, Nigeria. \\ 4. Master of Science in Occupational Therapy, Dept. of Medical Rehabilitation, College of Health Sciences, Obafemi Awolowo \\ University, lle - Ife, Nigeria. \\ 5. Master in Public Health, Dept. of Medical Rehabilitation, College of Health Sciences, Obafemi Awolowo University, lle - Ife, Nigeria. \\ 6. Master of Science in Physiotherapy, Dept. of Medical Rehabilitation, College of Health Sciences, Obafemi Awolowo University, Ile - \\ Ife, Nigeria. \\ 7. Professor, Dept. of Medical Rehabilitation, College of Health Sciences, Obafemi Awolowo University, lle - Ife, Nigeria.
}

$$
\begin{aligned}
& \text { Citation: Awotidebe TO, Oyeyemi AL, ljadunola MY, Olatoye FS, Adejumobi AS, Akinogbe } \\
& \text { FT, et al. Occupational Physical Activity and Health-Related Quality of Life among Nigerian } \\
& \text { Vocational-Skilled Workers. JOHE 2020; 9(4):239-47. }
\end{aligned}
$$

\section{Article Info}

* Corresponding author:

Taofeek O. Awotidebe,

E-mail:

tawotidebe@cartafrica.org

Article history

Received: Dec 2020

Accepted: Jan 2021

10.29252/johe.9.4.239

Print ISSN: 2251-8096 Online ISSN: 2252-0902

Peer review under responsibility of Journal of Occupational Health and Epidemiology

\section{Abstract}

Background: Occupational physical activity (OPA) is prevalent in the general population. However, its influence on the health status of manual workers is unclear. This study examined the impact of OPA on the health-related quality of life (HRQoL) of vocationalskilled workers (VSWs) in Nigeria.

Materials and Methods: This cross-sectional study was conducted on 354 male VSWs from six cities in Osun State, Nigeria. VSWs were selected using a multistage sampling method. OPA level and HRQoL were assessed using items from the International Physical Activity Questionnaire-Long Form and the Short Form (SF-36) Health Status Questionnaire, respectively. High OPA was defined as $>3000$ MET-min/week. Data were analyzed using bivariate and multivariate statistics.

Results: Participants' mean age was $38.3 \pm 9.6$ years, and $68.4 \%$ of the participants reported high OPA. As regards $\mathrm{HRQ}$ L, higher scores in physical functioning (PF) and physical composite summary (PCS) were found among the participants with high OPA. Amongst those with moderate OPA, higher scores were found in social functioning, mental health $(\mathrm{MeH})$, and mental composite summary (MCS). Significant differences were found in role limitation due to physical health problems $(t=0.55 ; p=0.002)$, bodily pain (BoP) ( $t=0.51 ; p=0.021)$, PCS ( $t=0.46 ; p=0.014)$, and $\mathrm{MeH}(t=0.27 ; p=0.026)$. Additionally, VSWs with high OPA were less likely to have problems with $\mathrm{BoP}(\mathrm{OR}=0.70$, $\mathrm{Cl}=0.52-0.95)$ and $\mathrm{MCS}(\mathrm{OR}=0.53, \mathrm{Cl}=0.35-0.78)$, but were twice more likely to have good PCS (OR=2.25, $\mathrm{Cl}=1.21-4.18)$.

Conclusions: The OPA level of Nigerian VSWs was high with significant impact on the HRQoL. Interventions focusing on promoting OPA to improve HRQoL are recommended.

Keywords: Physical Activity, Worker, Quality of Life, Health Status.

\section{Introduction}

Engagement in regular physical activity (PA) is beneficial for preventing and controlling the scourge of chronic non-communicable diseases
(NCDs) [1]. By definition, PA is any bodily movement initiated by skeletal muscles leading to increased energy expenditure and consequent health benefits [2]. Indeed, evidence from an 
epidemiological study showed that PA can reduce systolic blood pressure by $15 \mathrm{mmHg}$ and helps to lower the risk of sudden death from cardiovascular disease by $30 \%$ [3]. In the last few decades, researchers have focused on leisure-time PA and its benefits in improving health status $[4,5]$. In addition, occupational physical activity (OPA) associated with some occupations such as manual labor and vocational jobs is on the rise among citizens of developing economies due to growing population and unemployment challenges [6]. These occupations require job-related activities that involve regular bodily movements, use of considerable large muscle groups, and substantial energy expenditure which may have the same effects similar to that of leisure-time PA $[7,8]$.

Vocational skills are manual works that individuals learn in a special area of interest. They are mainly hands-on technical skills rather than rigorous academic programs [9]. Furthermore, these skills are acquired from hands-on experience usually gained outside the traditional classroom setting. Many of these skills involve manual labor and sometimes require long hours of activities. Although manual labor increases energy expenditure and higher muscular strength as features commonly seen in manual workers, the health benefits of OPA including health-related quality of life (HRQoL) have not been objectively explored among Nigerian vocational-skilled workers.

In recent times, owing to an increasing in the unemployment rate in Nigeria, many young adults have taken up new skills including some technical works and now engage in various vocational skills as a means of livelihood in the informal sector of the economy. Hence, several vocational-skilled workers have now occupied the largest hub of the Nigerian labor market thus contributing to local enterprise productivity and profitability, wealth creation, as well as national economic growth [10]. Noticeably, the economic growth and gross domestic product of any nation appear to be partly dependent on the health status of workers of the nation. On the other hand, the nature of any occupational activity may also increase exposure to different health hazards, thus negatively affecting $\mathrm{HRQ}$ oL and leading to low productivity at work [11, 12]. However, the impact of OPA on $\mathrm{HRQoL}$ as regards vocational skills appears to be poorly understood and has received little or no attention. Furthermore, reports on OPA as a determinant of HRQoL among Nigerian vocationalskilled workers are scarce. Thus, understanding the influence of OPA on HRQoL among vocational skill workers in Nigeria is important to designing interventions to improve occupational health, work productivity, and efficient allocation of resources for effective disease prevention and national health planning programs. Therefore, this study aims to investigate the impact of the OPA level on the HRQoL of Nigerian vocational-skilled workers.

\section{Materials and Methods}

This cross-sectional study was performed on male vocational-skilled workers (trained manual workers) in Osun State, Nigeria. The workers were selected through a multi-stage sampling method. First, using simple random sampling; four out of eight popular vocational skills in Osun State were selected, namely: automobile engineering, brick layering, carpentry, and metal welding. Then, six out of ten major cities in the state were randomly selected namely; Gbongan, lle-Ife, Ikire, Ilesa, Ipetumodu, and Osogbo. Furthermore, three out of six zones in each city were randomly selected, and lastly, a systematic sampling method was used to select every third member from the list of registers for each vocational type. The inclusion criteria for the study were healthy individuals who were within the age range of $25-65$ years with at least oneyear work experience in the selected vocational skills. However, individuals with self-reported chronic conditions and apprentices undergoing training were excluded from the study.

Before recruitment, the presidents/ chairmen of the associations of selected vocational skills in the selected cities and zones were visited during their general meetings which were usually held bimonthly. The main objectives of the study were explained to them and an appointment was booked to meet the members. Thereafter, a date for the next general meeting was fixed for an interactive session with the members. During the meeting at each venue, the aim of the study was described to all vocational skill workers attending the meeting. Various questions about the purpose of the study were asked by members and answers were provided by the researcher to their satisfaction. Those who volunteered to participate in the study were recruited. The sample size for this study was determined based on a sample size formula for cross-sectional studies; $n=Z 2(p(1-p) / e 2$, where, $\mathrm{n}=$ the needed sample size, $\mathrm{Z}=\mathrm{z}$-value $(\mathrm{z}-$ value for $95 \%$ confidence level $=1.96$ ), $p=$ the estimated proportion of an attribute present in the population, and $\mathrm{e}=$ the desired level of precision (i.e. confidence interval, expressed as decimal $(0.05)$ [13]. A review of the literature showed the prevalence $(p)$ of physical inactivity in the Nigerian population was estimated to be $25.0 \%$ [14]. Hence, a total of 345 persons were considered as the research sample. Furthermore, the estimated 
sample was increased to 380 persons with the view to preventing the incidence of non-responders and lost data. Nonetheless, a total of 354 persons were eventually included in the research sample. In all, 16 members refused to participate, eight provided incomplete responses to the items in the questionnaires, and two persons provided unreliable data. The total response rate in this study was $93.2 \%$. The data were collected from October to December 2018.

Permission to conduct the study among members was obtained following the explanation of the purpose of the study to the chairmen and members of the respective vocational skills group. The participants signed an informed consent form. The Obafemi Awolowo University Teaching Hospitals Complex, Ile - Ife, Osun State, ethical committee; the Ethics and Research Committee approved the study (Protocol number: ERC/2018/10/12).

The socio-demographic background data and vocational skill type of participants were recorded. Thereafter, OPA was assessed using the International Physical Activity Questionnaire-Long Form (IPAQ-LF) while the health-related quality of life was assessed using the Short Form-36 (SF-36) Health Survey Questionnaire. Copies of the questionnaires were self-administered and collected immediately after completion.

Assessment of occupational physical activity: Occupational physical activity was assessed using the IPAQ-LF. The questionnaire was reported to have satisfactory test-retest reliability and criterion validity in the Nigerian population [15]. The IPAQLF collects information about the frequency (days/week) and duration (minutes/day) of PA in specific domains such as occupation, active transport, domestic, and leisure and sitting time during weekdays and weekends [14]. In this study, only the 7-item occupational domain of the IPAQLF that measures vigorous-intensity activities, moderate-intensity activities, and walking was used to obtain information on PA undertaken during any occupational activity performed within the last week before the start of the study. OPA included activities at work such as standing, walking, working while sitting down, carrying heavy objects, and cleaning of workshop surroundings. To obtain the energy equivalence of OPA, the intensity of activity (i.e., vigorous, moderate, and walking) was multiplied by their estimated MET value. The MET values assigned to the intensities of OPA in this study were 8 METs (vigorous), 4 METs (moderate), and 3.3 METs (walking) [15]. Total OPA was computed by summing the calculated MET-minutes/week of vigorous-intensity activities, moderate-intensity activities, and walking activities done at work. OPA was first categorized as low, moderate, and high.

The low OPA category is the lowest level of physical activity. Those individuals who did not meet the criteria for the moderate or high categories were considered 'low'. The participants in the moderate OPA category were those that achieved a minimum OPA of at least 600METminutes/week at work. The high OPA category was described as achieving a minimum total OPA of at least $3000 \mathrm{MET}$-minutes/week at work [16]. OPA levels were initially classified as low, moderate, or high according to the categorization described by the IPAQ core group (http://www.ipaq.ki.se). However, owing to the very high degree of OPA observed among the study population and that no participant had a low OPA level, the classifications were then re-categorized in line with the purpose of this study as moderate OPA (<3000 MET-minutes/week) or high OPA (at least 3000 MET-minutes/week). High OPA groups were those who engaged in $>3000$ METminutes/week of moderate-intensity activity per week. This definition is above the new WHO global standard for healthy physical activity recommendations, which was defined as engaging in at least 150 minutes of moderate-intensity activity per week [17].

Assessment of health-related quality of life: The health-related quality of life (HRQoL) of the participant was assessed using the Short Form-36 (SF-36) Health Survey Questionnaire. The questionnaire has been used in many clinical and research settings in Africa $[18,19]$. It consists of 8 subscales including physical functioning (10 items), general health (5 items), mental health (5 items), vitality (4 items), role limitations due to physical health problems (RLdPhp: 4 items), role limitation due to emotional problems (RLdEmp: 3 items), bodily pain ( 2 items), and social functioning ( 2 items). The subscales can be summarized into 2 important domains namely; physical and mental composite summaries (PCS \& MCS). The individual SF-36 items were recoded, summed, and transformed. The health concepts described by the SF-36 range in scores from $0-100$, with higher scores indicating higher levels of function or better health (19). The cultural adaptation and psychometric properties of SF-36 in the Yoruba language were described in our previous study [20].

The collected data were analyzed using descriptive statistics to summarize the data. Besides, the independent samples t-test was used to compare the HRQoL subscales between the individuals with high and moderate OPA. Multivariate logistic 
regression analysis was also run to evaluate the associations between high OPA, sociodemographic variables, and HRQoL of the vocational-skilled workers. Adjusted odds ratios (ORs) with 95\% confidence intervals (Cls) were calculated against the reference category of the participants aged $<50$ years, had a primary educational level, automobile mechanics vocational skilled workers, those that were single or never married, those whose monthly income was $<\$ 50,000$, and the physical functioning subscale of the HRQoL. Statistical analysis was carried out with the aid of IBM SPSS Statistics
20.0 (IBM Corp., Armonk, NY, USA). Alpha level of $p \leq 0.05$ was considered statistically significant.

\section{Results}

The participants were all male vocational-skilled workers with a mean age of $38.3 \pm 9.6$ years. About a quarter, $26.8 \%$, were bricklayers and half of them, 50.8\%, were recruited from cities including Ile-Ife and Osogbo. More than two-thirds of the participants, $68.4 \%$, reported high OPA (Table 1).

Table 1. Distribution of socio-demographic characteristics and occupational physical activity level of participants

\begin{tabular}{|c|c|c|c|}
\hline \multicolumn{2}{|c|}{ Variables } & \multirow{2}{*}{$\frac{\mathbf{n}}{209}$} & \multirow{2}{*}{$\frac{(\%)}{59.0}$} \\
\hline A aroun (unaral & $<50$ & & \\
\hline Age group (years) & $>50$ & 145 & 41.0 \\
\hline \multirow{2}{*}{ Marital status } & Single & 218 & $\overline{61.6}$ \\
\hline & Married & 136 & 38.4 \\
\hline \multirow{4}{*}{ Vocational type } & Automobile Mechanic & 80 & $\overline{22.6}$ \\
\hline & Bricklayer & 95 & 26.8 \\
\hline & Carpenter & 91 & 25.7 \\
\hline & Welder & 88 & 24.9 \\
\hline \multirow{6}{*}{ Selected city } & Gbongan & 30 & 8.5 \\
\hline & Ikire & 30 & 8.5 \\
\hline & lle-Ife & 90 & 25.4 \\
\hline & llesha & 89 & 25.1 \\
\hline & Ipetumodu & 25 & 7.1 \\
\hline & Osogbo & 90 & 25.4 \\
\hline \multirow{3}{*}{ Educational level } & Primary & 102 & 28.8 \\
\hline & Secondary & 174 & 49.2 \\
\hline & Post-secondary & 78 & 22.0 \\
\hline \multirow{3}{*}{$\begin{array}{l}\text { Monthly Income } \\
\text { (Naira) }\end{array}$} & $<\$ 50,000$ & 223 & 63.0 \\
\hline & $\# 50,000-100,000$ & 96 & 27.1 \\
\hline & 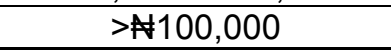 & 35 & 9.9 \\
\hline \multirow{2}{*}{ OPA level } & $\begin{array}{c}\text { Moderate } \\
(<3000 \text { MET-min/week) }\end{array}$ & 112 & 31.6 \\
\hline & $\begin{array}{c}\text { High } \\
\text { (>3000 MET-min/week) }\end{array}$ & 242 & 68.4 \\
\hline
\end{tabular}

OPA: Occupational physical activity, Naira (Nigerian Currency)

The results of a comparison of the health-related quality of life of Nigerian vocational-skilled workers between those with high and moderate OPA are presented in Table 2.

As can be seen, the HRQoL subscales of participants with high OPA had better (higher) role limitation due to physical health problems (RLdPhp) and physical composite summary (PCS) than those with moderate OPA. On the contrary, those with high OPA scored lower in terms of social functioning (SoF), mental health, and MCS; $54.7 \pm 15.3,52.4 \pm 9.4$, and $52.8 \pm 8.5$ respectively. However, the participants with moderate OPA had better (higher) scores in bodily pain and mental health than those with high OPA. Furthermore, a comparison of the participants with high and moderate OPA showed significant differences in role limitation due to physical health problems (RLdPhp): $95.0 \pm 14.0$ versus $83.3 \pm$ $32.3(\mathrm{t}=0.55 ; \mathrm{p}=0.002$ ), bodily pain: $60.0 \pm 14.8$ versus $65.8 \pm 18.2(\mathrm{t}=0.55 ; \mathrm{p}=0.002)$, mental health: $52.4 \pm 9.4$ versus $58.1 \pm 9.6(t=0.27 ; p=$ $0.026)$, and PCS: $75.5 \pm 15.0$ versus $62.3 \pm 17.5$ $(t=0.46 ; p=0.014)$. 
Table 2. A comparison of health-related quality of life of vocational-skilled workers with high and moderate occupational physical activity

\begin{tabular}{ccccc}
\hline Variables & $\begin{array}{c}\text { High OPA } \\
(\text { mean } \pm \text { S.D })\end{array}$ & $\begin{array}{c}\text { Moderate OPA } \\
(\text { mean } \pm \text { S.D })\end{array}$ & t-test & P-value \\
\hline Physical functioning & $93.3 \pm 8.4$ & $92.3 \pm 8.2$ & 0.22 & 0.206 \\
\hline RLdPhp & $95.0 \pm 14.0$ & $83.3 \pm 32.3$ & 0.55 & $0.002^{*}$ \\
\hline RLdEmp & $61.5 \pm 20.5$ & $60.4 \pm 18.2$ & 0.21 & 0.086 \\
\hline Bodily pain & $60.0 \pm 14.8$ & $65.8 \pm 17.6$ & 0.51 & $0.021^{*}$ \\
\hline General health & $70.4 \pm 18.9$ & $69.9 \pm 18.0$ & 0.34 & 0.096 \\
\hline Vitality & $72.2 \pm 10.5$ & $69.3 \pm 12.1$ & 0.26 & 0.142 \\
\hline Social functioning & $54.7 \pm 15.3$ & $58.3 \pm 15.4$ & 0.44 & 0.137 \\
\hline Mental health & $52.4 \pm 9.4$ & $58.1 \pm 9.6$ & 0.27 & $0.026^{*}$ \\
\hline PCS & $75.5 \pm 15.0$ & $62.3 \pm 17.5$ & 0.46 & $0.014^{*}$ \\
\hline MCS & $52.8 \pm 8.5$ & $52.0 \pm 9.5$ & 0.28 & 0.162 \\
\hline
\end{tabular}

${ }^{*} \mathrm{p}<0.05$

PA, Physical activity; RLdPhp, Role limitation due to physical health problems; RLdEmp, Role limitation due to emotional problems; PCS, Physical composite summary; MCS, Mental composite summary

Table 3 shows the associations between the sociodemographic characteristics, the HRQoL subscales, and high OPA of the vocational-skilled workers. As is shown, the participants with high OPA were less likely to have minimal bodily pain
$(\mathrm{OR}=0.70, \mathrm{Cl}=0.52-0.95)$ and less likely to have $\mathrm{MSC}$ issues $(\mathrm{OR}=0.53, \mathrm{Cl}=0.35-0.78)$. However, the participants with high OPA were twice more likely to have good PCS $(\mathrm{OR}=2.25, \mathrm{Cl}$ $=1.21-4.18)$.

Table 3. Associations between socio-demographic characteristics, the health-related quality of life, and high occupational physical activity of the vocational-skilled workers

\begin{tabular}{|c|c|c|c|}
\hline \multirow{2}{*}{\multicolumn{2}{|c|}{ Variables }} & \multicolumn{2}{|c|}{ High OPA } \\
\hline & & ORa & $95 \% \mathrm{Cl}$ \\
\hline \multirow{2}{*}{ Age group (years) } & $<50$ & 1.00 & \\
\hline & $>50$ & 1.29 & $0.96-1.74$ \\
\hline \multirow{3}{*}{ Marital status } & Single & 1.00 & \\
\hline & Married & 1.06 & $0.90-1.24$ \\
\hline & Widow/widower & 1.28 & $0.58-2.82$ \\
\hline \multirow{3}{*}{ Educational level } & Primary & 1.00 & \\
\hline & Secondary & 1.07 & $0.90-1.27$ \\
\hline & Post-secondary & 1.63 & $1.34-1.97$ \\
\hline \multirow{4}{*}{ Vocational skill } & Automobile mechanics & 1.00 & \\
\hline & Bricklayer & 1.23 & $0.92-1.64$ \\
\hline & Carpenter & 1.07 & $0.75-1.52$ \\
\hline & Welder & 1.45 & $0.87-2.40$ \\
\hline \multirow{3}{*}{ Monthly income } & $<\$ 50,000$ & 1.00 & \\
\hline & $\$ 50,000-\$ 100,000$ & 1.40 & $0.79-2.48$ \\
\hline & $>\$ 100,000$ & 1.08 & $0.67-1.75$ \\
\hline \multirow{10}{*}{ HRQoL } & Physical functioning & 1.00 & \\
\hline & RLdPhp & 1.18 & $0.77-1.81$ \\
\hline & RLdEmp & 1.11 & $0.90-1.37$ \\
\hline & Bodily pain & 0.70 & $0.52-0.95^{\star}$ \\
\hline & General health & 0.99 & $0.74-1.87$ \\
\hline & Vitality & 0.83 & $0.64-1.14$ \\
\hline & Social functioning & 1.15 & $0.89-1.46$ \\
\hline & Mental health & 1.50 & $1.11-2.03$ \\
\hline & PCS & 2.25 & $1.21-4.18^{\star}$ \\
\hline & MCS & 0.53 & $0.35-0.78^{*}$ \\
\hline
\end{tabular}

${ }^{*} p<0.05$

Keys: OPA, Occupational physical activity; OR ${ }^{a}$, Adjusted odds ratio; Naira (Nigerian Currency); HRQoL, Health-related quality of life; RLdPhp, Role limitation due to physical health problems; RLdEmp, Role limitation due to emotional problems; PCS, Physical composite summary; MCS, Mental composite summary. 


\section{Discussion}

This study explored the association between OPA and HRQoL among vocational-skilled workers in Nigeria. A majority of the vocational skilled workers in this study reported high OPA levels. Similarly, a previous study showed that manual workers usually have higher OPA levels than white-collar workers [21]. This could be attributed to frequent regular bodily movements involving a large muscle group which is a common feature of vocationalskilled workers. Moreover, repetitive and regular bodily movements increase total energy expenditure which in turn may lead to higher muscular strength, flexibility, endurance, and cardiorespiratory fitness [7, 22].

The findings from the present study also showed that a majority of the participants have high OPA irrespective of age group and vocational-skilled types. Mundwiler et al, [7] described the nature of manual work or vocational skills that require the application of muscular force in carrying out occupational activities. Regular application of force increases higher energy expenditure and improves physical fitness regardless of the age group. Äijö et al, [23] also concluded that any activity that increases energy expenditure is essential for improving overall health notwithstanding any age category. However, the present study suggested that the participants with high OPA were less likely to have minimal bodily pain. This is in agreement with findings of previous studies showing that persistent repetitive strain injury may result in the accumulation of micro-injuries to the musculoskeletal system leading to the development of consistent bodily pain [24]. Accordingly, it can be argued that long hours of occupational activities may negatively affect the muscles and joints of the body. Furthermore, repetitive overuse of muscles and joints may also lead to psychosocial stress and unceasing bodily pain.

Considering some of the subscales on the HRQoL, the participants with moderate OPA were found to have better HRQoL than the individuals with high OPA including bodily pain, social functioning, and mental health. In a similar vein, previous studies have shown that occupational hazards are associated with jobs that placed heavy demands on both physical and mental capabilities [25, 26]. This implies that the workers with high OPA were likely to be overworking and probably putting more pressure on their body system compared with those with moderate OPA. Furthermore, prolonged hours of work could lead to dissatisfaction and poor HRQoL. Our study also found that social functioning, mental health, and mental composite summary had the worst scores in the HRQoL subscales. This finding corroborates a previous study that showed jobs involving manual labor with long hours of participation may lead to low selfesteem and poor mental well-being [27]. Although several other factors may be responsible for the poor HRQoL in some of the subscales, occupational stress, environmental challenges, and the socio-economic situation could contribute to the feeling of depression, low emotional wellbeing, and subsequently poor HRQoL. Thus, more studies are needed to explore the multideterminants of HRQoL among vocational-skilled workers.

Our study also found that the physical component summary of $H R Q o L$ was significantly associated with OPA regardless of vocational-skill type. Accordingly, a previous study suggested any form of activity involving regular bodily movements helps to improve physical functioning and fitness [28]. In addition, Bernards et al, [29] in a prospective cohort study involving over 1700 Dutch workers, concluded that manual workers have higher OPA leading to good physical health benefits. These benefits may be connected with the accumulation of high volumes of vigorousintensity activities which culminated in good healthrelated physical fitness including increased muscular strength and endurance, flexibility, and appropriate body composition. All these benefits may also help to reduce the incidence of several other chronic non-communicable diseases and even untimely death.

On the contrary, the findings from the present study showed that vocational-skilled workers with high OPA were less likely to have satisfactory mental health outcomes. In contrast, previous studies have indicated that any form of PA is significantly associated with a lower risk of depression, emotional exhaustion, and poor mental health outcomes [29-31]. This discrepancy could be a result of the mental tasks involved during OPA. Furthermore, comparing OPA with leisure-time PA, it appears that leisure-time PA is more relaxing, enjoyable and does not require elaborate mental exertion during participation. Moreover, the longer duration of time expended during OPA usually exceeds the recommended maximum daily period of 30 minutes a day for health benefits concerning participation in leisuretime PA [8, 32]. Mental fatigue caused by the extended duration of activities may account for poor mental health outcomes during OPA.

Although OPA resulted in increased energy expenditure, its impact on HRQoL appears to be less beneficial for vocational-skilled workers' mental well-being. This highlights the difference 
between OPA and leisure-time PA. Hence, performing regular leisure-time $P A$ in addition to OPA may help to prevent the development of many chronic non-communicable diseases such as coronary artery disease, hypertension, diabetes, musculoskeletal disorders, some cancers, and more importantly, mental disorders [7, 33, 34]. Several clinical trials and epidemiological studies have provided convincing evidence that recreational and leisure-time PA has multiple health benefits [35, 36]. For instance, Das et al, [37] found a relationship between leisure-time PA and relief of low-moderate anxiety, promotion of positive mood, and increased self-esteem and cognitive function. Undoubtedly, vocational-skilled workers with a good health status irrespective of vocational type have reduced numbers of absenteeism at work due to illness, reduced cost of medical care, and high overall productivity leading to considerable national economic growth. It is worth mentioning that there were some limitations in this study and findings should be interpreted with caution. First, the self-reported OPA level could lead to a subjective assessment. The assessment might have been over or underestimated by the participants. Furthermore, the OPA section of IPAQ is generic, and thus an OPAspecific scale might have been more appropriate. Yet, the IPAQ provides a comprehensive assessment of OPA which could have been difficult utilizing other OPA scales. We recommend that future studies should consider using a more objective assessment of OPA to validate the findings of this study. Moreover, the study design was a cross-sectional survey; hence, a causal relationship could not be established. Restricting the sample to male participants in the cities may limit the generalization of findings to other vocational-skilled workers in Nigeria. However, the participants were selected through a multistage sampling technique thereby reducing the potential bias.

\section{Conclusion}

In conclusion, the OPA level among Nigerian vocational-skilled workers is very high with varying impacts on the HRQoL domains. OPA was more significantly associated with physical health but less with mental health outcomes. The findings provide evidence that interventions focusing on promoting OPA are relevant to enhancing the HRQoL of vocational-skilled workers in Nigeria. Regular assessment of HRQoL of vocationalskilled workers should be taken into consideration to detect individuals at risk of chronic diseases such as musculoskeletal disorders and depression.
This may help to document the pattern of health challenges and the health status of vocationalskilled workers for future studies.

\section{Acknowledgement}

We wish to thank the Consortium for Advanced Research Training in Africa (CARTA) for their technical support. CARTA is jointly led by the African Population and Health Research Center and the University of the Witwatersrand and funded by the Wellcome Trust (UK) (Grant No: 087547/Z/08/Z), the Carnegie Corporation of New York (Grant No: B 8606), the Ford Foundation (Grant No: 1100-0399), the Department for International Development (DfID) under the Development Partnerships in Higher Education (DelPHE), Swedish International Development Corporation Agency - SIDA (Grant No: 54100029), MacArthur Foundation (Grant No: 10-95915-000INP), and Google.Org (Grant No: 191994).

\section{Conflict of interest: None declared.}

\section{References}

1. World Health Organization. Global status report on non-communicable diseases 2014. Geneva, Switzerland: World Health Organization; 2014.

2. Dasso NA. How is exercise different from physical activity? A concept analysis. Nurs Forum 2019; 54(1):45-52.

3. Awotidebe TO, Adeyeye VO, Ativie RN, Adedoyin RA, Borode AO, Balogun MO, et al. Functional Capacity and Psychosocial Correlates of Exercise in Nigerian Patients with Hypertension. Int J Clin Med 2016; 7(7):464-73.

4. Kaleta D, Makowiec-Dabrowska T, Dziankowska-Zaborszczyk E, Jegier A. Physical activity and self-perceived health status. Int $\mathrm{J}$ Occup Med Environ Health 2006; 19(1):61-9.

5. Jantunen $H$, Wasenius $N$, Salonen $M K$, Kautiainen $\mathrm{H}$, von Bonsdorff MB, Kajantie $\mathrm{E}$, et al. Change in physical activity and healthrelated quality of life in old age-A 10-year followup study. Scand J Med Sci Sports 2019; 29(11):1797-804.

6. World Bank. World Development Report 2007: Development and the Next Generation. Washington D.C, United States: World Bank; 2006.

7. Mundwiler J, Schüpbach U, Dieterle $T$, Leuppi JD, Schmidt-Trucksäss A, Wolfer DP, et al. Association of Occupational and Leisure-Time Physical Activity with Aerobic Capacity in a Working Population. PLoS One 2017; 12(1):e0168683.

8. Flower DJC, Tipton MJ, Milligan GS. Considerations for physical employment 
standards in the aging workforce. Work 2019; 63(4):509-19.

9. Yang J. General or vocational? The tough choice in the Chinese education policy. Int $\mathrm{J}$ Edu Dev 2008; 18(4):289-304.

10. Yusuff, MA, Soyemi J. Achieving Sustainable Economic Development in Nigeria through Technical and Vocational Education and Training: The Missing Link. International Journal of Academic Research in Business and Social Sciences 2012; 2(2):71-7.

11. van den Berge $M$, Hulsegge $G$, van der Molen HF, Proper KI, Pasman HRW, den Broeder L, et al. Adapting Citizen Science to Improve Health in an Occupational Setting: Preliminary Results of a Qualitative Study. Int J Environ Res Public Health 2020; 17(14):4917.

12. Ekpenyong CE, Inyang UC. Associations between worker characteristics, workplace factors, and work-related musculoskeletal disorders: a cross-sectional study of male construction workers in Nigeria. Int $\mathrm{J}$ Occup Safety Ergon 2014; 20(3):447-62.

13. Kasiulevičius $V$, Šapoka $V$, Filipavičiūtè $R$. Sample size calculation in epidemiological studies. Gerontologija 2006; 7(4):225-31.

14. Ofori-Asenso R, Agyeman AA, Laar A, Boateng D. Overweight and obesity epidemic in Ghana-a systematic review and meta-analysis. BMC Public Health 2016; 16(1):1239.

15. Oyeyemi AL, Bello UM, Philemon ST, Aliyu HN, Majidadi RW, Oyeyemi AY. Examining the reliability and validity of a modified version of the International Physical Activity Questionnaire, long form (IPAQ-LF) in Nigeria: a cross-sectional study. BMJ Open 2014; 4(12):e005820.

16. Craig $C L$, Marshall $A L$, Sjöström $M$, Bauman AE, Booth ML, Ainsworth BE, et al. International physical activity questionnaire: 12- country reliability and validity. Med Sci Sports Exerc 2003; 35(8):1381-95.

17. World Health Organization. Global recommendations on physical activity for health. Geneva, Switzerland: World Health Organization 2010.

18. Ekwunife OI, Aguwa CN, Adibe MO, Barikpaoar E, Onwuka CJ. Health state utility of a population of Nigerian hypertensive patients. BMC Res Notes 2011; 4:528.

19. Ware JE Jr, Gandek B. Overview of the SF-36 Health Survey and the International Quality of Life Assessment (IQOLA) Project. J Clin Epidemiol 1998; 51(11):903-12.

20. Mbada CE, Adeogun GA, Ogunlana MO, Adedoyin RA, Akinsulore A, Awotidebe TO, et al. Translation, cross-cultural adaptation and psychometric evaluation of Yoruba version of the short-form 36 health survey. Health Qual Life Outcomes 2015; 13:141.

21. Mänttäri SK, Oksa JAH, Virkkala J, Pietilä JAK. Activity Level and Body Mass Index as
Predictors of Physical Workload During Working Career. Saf Health Work 2019; 10(4):527-30.

22. Warburton DER, Bredin SSD. Health benefits of physical activity: a systematic review of current systematic reviews. Curr Opin Cardiol 2017; 32(5):541-56.

23. Äijö M, Kauppinen M, Kujala UM, Parkatti T. Physical activity, fitness, and all-cause mortality: An 18-year follow-up among old people. J Sport Health Sci 2016; 5(4):437-42.

24. Baba NH, Daruis DDI. Repetitive Strain Injury (RSI) among Computer Users: A Case Study in Telecommunication Company. Malaysian Journal of Public Health Medicine 2016; Special Volume (1):48-52

25. Lee WT, Lim SS, Kim J, Yun S, Yoon JH, Won JU. Work Schedule Irregularity and the Risk of Work-Related Injury among Korean Manual Workers. Int J Environ Res Public Health 2020; 17(20):7617.

26. Bell SL, Audrey S, Gunnell D, Cooper A, Campbell $R$. The relationship between physical activity, mental wellbeing and symptoms of mental health disorder in adolescents: a cohort study. Int J Behav Nutr Phys Act 2019; 16(1):138.

27. International Labour Organisation. Workplace Stress: A Collective Challenge. Geneva, Switzerland: International Labour Organisation; 2016.

28. US Department of Health of and Human Services. Physical Activity and Health. A Report of the Surgeon General. Atlanta, Georgia, United States: Department of Health andHuman Services, Centers for Disease Control and Prevention, NationalCenter for Chronic Disease Prevention and Health Promotion; 1996.

29. Bernaards CM, Jans MP, van den Heuvel SG, Hendriksen IJ, Houtman IL, Bongers PM. Can strenuous leisure time physical activity prevent psychological complaints in a working population? Occup Environ Med 2006; 63(1):106.

30. Mattli R, Farcher R, Syleouni ME, Wieser S, Probst-Hensch N, Schmidt-Trucksäss $A$, et al. Physical Activity Interventions for Primary Prevention in Adults: A Systematic Review of Randomized Controlled Trial-Based Economic Evaluations. Sports Med 2020; 50(4):731-50.

31. Harvey SB, Øverland S, Hatch SL, Wessely S, Mykletun A, Hotopf $M$. Exercise and the Prevention of Depression: Results of the HUNT Cohort Study. Am J Psychiatry 2018; 175(1):2836.

32. World Health Organization. Global Strategy on Diet and Physical Activity and Health. Geneva, Switzerland: World Health Organization; 2004.

33. Pate RR, Pratt M, Blair SN, Haskell WL, Macera CA, Bouchard C, et al. Physical activity and public health. A recommendation from the Centers for Disease Control and Prevention and the American College of Sports Medicine. JAMA 1995; 273(5):402-7. 
34. da Silva JMN, Gontijo LA, de Araujo Vieira EM, dos Santos Leite WK, Colaço GA, Heuer de Carvalho VD, et al. A worksite physical activity program and its association with biopsychosocial factors: An intervention study in a footwear factory. Int J Ind Ergon 2019; 69:739.

35. Okano G, Miyake $\mathrm{H}$, Mori M. Leisure time physical activity as a determinant of selfperceived health and fitness in middle-aged male employees. J Occup Health 2003; 45(5):286-92.
36. Myers J, McAuley P, Lavie CJ, Despres JP, Arena R, Kokkinos P. Physical activity and cardiorespiratory fitness as major markers of cardiovascular risk: Their independent and interwoven importance to health status. Prog Cardiovasc Dis 2015; 57(4):306-14.

37. Das KV, Jones-Harrell C, Fan Y, Ramaswami A, Orlove B, Botchwey N. Understanding subjective well-being: perspectives from psychology and public health. Public Health Rev 2020; 41(1):25. 